\title{
CARBON ISOTOPE AND IR EVIDANCE IN FAVOR OF FLUID ORIGIN OF NATURAL DIAMONDS FROM KIMBERLITE PIPES IN YAKUTIAN PROVINCE
}

\author{
A.V Ukhanov ${ }^{1}$, GK Khachatryan ${ }^{2}$ \\ ${ }^{I}$ Vemadsky Institute of geochemistry and analytical chemistry, Russia \\ ${ }^{2}$ Central Research Prospecting Institute of Nonferrous and Noble Metals, Russia \\ nata@geokhi.ru
}

\begin{abstract}
It has been known a number of processes of diamond formation, but only some of them give rise to diamond deposits. Apart from high $\mathrm{P}$ and $\mathrm{T}$, fitting the diamond stability, the medium enriched in carbon or some input of carbon seems to be a necessary condition for plentiful precipitation and growth of diamond crystals. As for kimberlite pipes, which is the most important type of the diamond deposits, there are strong ground for believing, that diamond grains of commercial value represent xenokrysts derived from diamondbearing mantle rocks, although the possibility of diamond generation in carbonated kimberlitic magma must not ruled out. It has been assumed that the great variety of diamonds reflects the variety of magmatic and metasomatic processes involving in diamond generation, as well as mantle heterogeneity. The character of the processes is responsible for carbon isotope fractionation and thus has influence on ${ }^{13} \mathrm{C}$ contents in growing crystals. Since the same conditions influence on typomorphic features of diamonds, a correlation is to be expected between $\delta^{13} \mathrm{C}$ and their morphology, inclusion mineralogy, impurities and so on. The correlation between ${ }^{13} \mathrm{C}$ and nitrogen contents in suites of yakutian diamonds is the subject of the present paper.

Carbon isotopic analyses of diamonds have been performed using $\mathrm{CO}_{2}$ obtained by combustion of the specimens at $950^{\circ}$ in oxygen liberated by $\mathrm{CuO}$. The results are reported as $\delta{ }^{13} \mathrm{C}$ values $(\% \mathrm{o})$ deviations from PDB reference. The nitrogen concentration ( $\mathrm{ppm}$ ) were established by infrared spectroscopy using the technique proposed by Mendelsohn and Milledge (1995).
\end{abstract}

Here we have restricted to diamonds of -1 group according to Galimov (1984). These diamonds are confined to $\delta{ }^{13} \mathrm{C}$ values between -5 and $-1 \% \mathrm{o}$, which coincides with the right limb of the general histogram. The most of these diamonds represent colorless or brown and pink octahedral; rhombic dodecahedra and transitive forms occur more seldom. The diamond -1 have ultramafic mineral inclusions nitrogen is present as aggregated forms. According our estimation for twenty kimberlite pipes and placers, no less than $15 \%$ of all crystals belong to -1 group. As have been revealed, diamonds $\quad-1$ are abundant in kimberlites of two pipes of economic interest - Zapolyarnaya and Poiskovaya (Verkhnemunsky field) and in a small poor pipe Leningrad (Ukukitsky field). As the consequents, the average $\delta{ }^{13} \mathrm{C}$ values for diamonds from these three pipes are shifted to the heavy end of the carbon isotopic range: $-4,04 ;-4,50 ;-4,59 \%$ o. In Leningrad most of diamonds belong to a-1 group, wears in two other upper-named pipes they are dominant, but not the only type. In both cases only two third of the diamonds are isotopically heavier than -5 , while the rest of them ranges to $-12 \%$ o. It seems obvious that these complexly built pipes contain a mixture of diamonds of different origin. Nevertheless it has been possible basing on typomorphic peculiarity to distinguish individual genetically related diamond populations. The $\delta{ }^{13} \mathrm{C}$ and $\mathrm{N}$ data for such populations of octahedral and dodecahedra are summarized in table and shown in figures. By definition, $\delta{ }^{13} \mathrm{C}$ varies from -5 to $-2 \% \mathrm{o}$ in all four populations. The variations of $\mathrm{N}$ contents are wider, from 674 to $21 \mathrm{ppm}$.

The diamonds show systematic $\delta{ }^{13} \mathrm{C}-\mathrm{N}$ contents covariation, so the higher $\delta{ }^{13} \mathrm{C}$ values being associated with the lower $\mathrm{N}$ contents. It worth to emphasize, that logarithmic values of nitrogen contents varies linearly with $\delta{ }^{13} \mathrm{C}$. Since nitrogen impurity in diamond is mostly controlled by $\mathrm{N}$ concentration in the environment, the logarithmic character of the correlation argues for exponential nitrogen reduction during diamond growth. The different slopes of the straight lines of individual populations express different rate of processes, which have been directed to nitrogen minimum. Consequently it means, that in the course of diamond growth the increasing contents of ${ }^{13} \mathrm{C}$ had been going on. This effect could take place, if carbon isotopes fractionate between diamond and 
methane. Methane is assumed by many authors to be the initial fluid into the earth mantle. Its $\delta{ }^{13} \mathrm{C}$ value has been estimate as $-4,6 \%$, according Galimov (1991). Thus increasing of $\delta{ }^{13} \mathrm{C}$ in the suites from -5 to $2 \delta{ }^{13} \mathrm{C}$ favor fluidal origin of -1 diamonds. As for the fluidal origin of diamonds taken as a whole there are many lines of evidence (see, for example, Bulanova G. P. 1995), but one of the mast convincing facts, appears to be some thin veins made up of diamond crystals in eclogite nodules. This is proof that in some cases diamond formation is connect with opening fissures on the host rocks, what means local decreasing of the pressure. We have drown the paradoxical conclusion, that the cause of -1 diamonds formation is degassing of the fluid as a result of tectonic stretching in the lithospheric mantle. Precipitation of diamonds can de attributed to a fluid reaction like the following: $\mathrm{C}_{2} \mathrm{H}_{6}>$ $\mathrm{C}_{\text {diamond }}+\mathrm{CH}_{4}+\mathrm{H}_{2}$, which must to shifted to right when pressure is decreasing. The presence of $\mathrm{C}_{2} \mathrm{H}_{6}$ in fluidal inclusions in some diamonds (Talnikova et al, 1991) allows us to regard the reaction as rather plausible.

Carbon isotopic composition $\left(\mathrm{d}^{13} \mathrm{C}, \%\right.$ o) and nitrogen contents (ppm) in dimonds of $\quad-1$ group from some kimberlite pipes

\begin{tabular}{|c|c|c|c|}
\hline \multicolumn{2}{|c|}{ Leningrad } & \multicolumn{2}{c|}{ Zapolyarnaya } \\
\hline \multicolumn{2}{|c|}{ octahedra } & rhombic dodecahedra \\
\hline$\delta{ }^{13} \mathrm{C}$ & $\mathrm{N}, \mathrm{ppm}$ & $\delta{ }^{13} \mathrm{C}$ & $\mathrm{N}, \mathrm{ppm}$ \\
\hline$-4,68$ & 265 & $-4,99$ & 674 \\
\hline$-4,63$ & 276 & $-4,74$ & 635 \\
\hline$-4,18$ & 299 & $-4,68$ & 181 \\
\hline$-3,98$ & 508 & $-4,61$ & 599 \\
\hline$-3,94$ & 312 & $-4,51$ & 357 \\
\hline$-3,92$ & 483 & $-4,50$ & 161 \\
\hline$-3,91$ & 493 & $-4,02$ & 84 \\
\hline$-3,58$ & 223 & $-3,57$ & 161 \\
\hline$-3,32$ & 148 & $-3,12$ & 100 \\
\hline$-2,97$ & 248 & $-2,75$ & 133 \\
\hline$-2,91$ & 101 & $-2,48$ & 32 \\
\hline$-2,41$ & 91 & $-1,95$ & 21 \\
\hline$-2,18$ & 81 & & \\
\hline
\end{tabular}
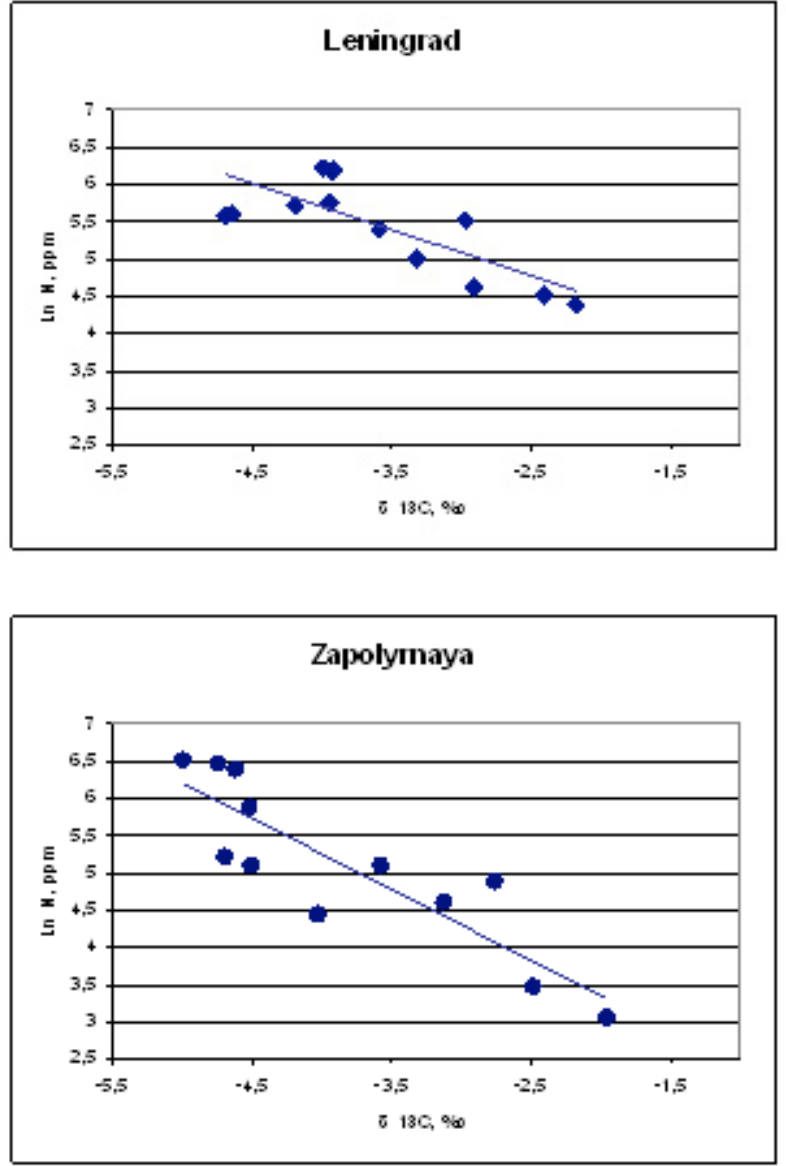

References

Bulanova G. P. (1995). The formation of diamond. $J$. Geochim. Explor. 53, 1-23

Galimov E. M. (1984) The relation between formation conditions and variations in isotope composition of diamond. Geokhimiya 8, 1091-1118

Galimov E. M. (1991) Isotope fractionation related to kimberlite magmatism and diamond formation. Geochimica et Cosmochimica Acta, 55, 1697-1708

Mendelssohn M.Y. and Milledge H. J. (1995) Geological significant information from routine analyses of the midinfrared spectra of diamonds. Int. Geol. Rev. 35, 95-110 Tal'nikova S. B., Barashkov In. P., Svoren' I. M. (1991) Composition and contents of eulogistic and ultramafic diamonds from kimberlite pipes in Yakutia Doklady Academi Nauk SSSR 331 (1), 194 - 197

Ukhanov A.V., Nikol'skaya, Galimov E. M., Koptil' V. J., Zintchouk N. N. (2005) Isotopic carbon composition of primary and placer deposits' diamond of Yakution diamondiferous province. In "Geology of diamonds - the present and the future"., 1095-1110 
